\title{
Tumours of the anterior uvea. III. Oxytalan fibres in the differential diagnosis of leiomyoma and malignant melanoma of the iris
}

\author{
M. S. NOOR SUNBA, A. H. S. RAHI, A. GARNER, \\ R. A. ALEXANDER, AND G. MORGAN \\ From the Department of Pathology, Institute of Ophthalmology, Judd Street, London
}

SUMMARY The diagnostic potential of oxytalan fibre demonstration in differentiating between leiomyomas and spindle-cell malignant melanomas of the iris was investigated. It was found that oxytalan fibres were abundant in leiomyomata, both between and around the tumour cells, whereas they were found in small numbers only and usually near the iris muscle in malignant melanomata. Their presence and distribution, therefore, appear to offer a satisfactory method of differentiating between these tumours. Since the human choroid and ciliary body normally contain oxytalan fibres, the above findings are not relevant to malignant melanoma of these structures. Naevi and regressing aggregates of iris melanoma cells away from the main tumour mass may similarly be surrounded by misleading amounts of these fibres.

Smooth muscle tumours of the iris have their origin in the dilator and sphincter muscles. Occasionally, however, they are found at other sites such as the anterior surface of the iris, where smooth muscle is not naturally present. ${ }^{1}$ Leiomyomas of the iris are less common than malignant melanomata, their incidence varying between $4 \%$ and $33 \%$ of primary iris tumours. ${ }^{2-5}$

According to Verhoeff, ${ }^{1}$ Ashton, ${ }^{4}$ and Reese $^{5}$ a leiomyoma is characterised by the presence of interlacing bundles of closely packed elongated spindle cells with long, oval, palisading nuclei. The granular eosinophilic cytoplasm of the tumour cell contains longitudinal striations composed of fine, discrete, nonbranching fibrils along the body of the cell, which tend to coalesce to form larger and coarser fibrils at the cell terminal. When these features are present, there is usually no difficulty in diagnosis, but, since smooth muscle tumours share a common neuroectodermal origin with melanocytic tumours, their histological features not uncommonly overlap, often making distinction difficult and sometimes impossible. This difficulty in the differentiation of leiomyomata from melanocytic tumours has been emphasised by several workers, ${ }^{4-6}$ and it has been stressed that the demonstration of myoglial fibrils in tumour cells by means of special stains such as

Correspondence to Dr A. H. S. Rahi, Institute of Ophthalmology, Judd Street, London WC1H 9QS. the Mallory phosphotungstic acid haematoxylin stain, the Masson trichrome stain, and the gold impregnation technique is the most important diagnostic criterion. Since myoglial fibrils, which are composed of contractile proteins, have been demonstrated in tissues other than smooth muscle ${ }^{7-10}$ it is clear that their presence cannot be regarded as a pathognomonic feature of leiomyoma. Moreover, smooth muscle fibrils may be found in malignant melanoma, ${ }^{11}$ while there are cases in which the histology is in every other way typical of leiomyoma but wherein myoglial fibrils cannot be demonstrated. ${ }^{45}$ In addition, because of their common neuroectodermal origin, it might be anticipated that poorly differentiated leiomyomata and melanomata of the iris would approximate to each other, and it is conceivable that there may be transitional cells between melanocytes and smooth muscle cells. While this may indicate that there is in fact no complete distinction between melanoma and leiomyoma regarding their histogenesis, there are, nonetheless, differences in their presentation as well as their clinical behaviour. Whereas death due to metastases from iris melanoma is well documented, ${ }^{12-16}$ a fatal outcome in leiomyoma is unknown. 4517

In a separate study of the distribution of various connective tissues in the eye we were impressed by the presence of a special type of fibre in certain tumours of the iris. These so-called oxytalan fibres, 
which were first identified by Fulmer and Lillie ${ }^{18}$ in the periodontal membrane, share histochemical staining properties with elastic tissue. They are called oxytalan fibres because of their greater resistance to hydrolysis by formic acid when compared with collagen. Various stains for elastic fibres such as aldehyde fuchsin, orcein, and resorcein fuchsin do not stain these fibres, unless the tissue sections are first exposed to strong oxidising agents such as peroxymonosulphate and peracetic acid. Oxytalan fibres were later demonstrated in other sites, particularly in tissues which were subject to mechanical stress, namely tendons, ligaments and the adventitia of blood vessels. ${ }^{19}$ At present these fibres are considered to be part, along with elaunin, of the normal elastic fibre system. ${ }^{2021}$ Ultrastructurally oxytalan fibres consist of a collection of microfibrils of tubular appearance with an external diameter of $12-15 \mathrm{~nm}$, but unlike elastic fibres they do not have a central amorphous core. ${ }^{20}$

Study of oxytalan fibres in eye has been limited, but Alexander and Garner ${ }^{22}$ have shown that they are common in a variety of pathological corneal states. We decided, therefore, to study oxytalan fibres in normal human iris and in leiomyomas and melanomas in order to see if a different distribution would help in arriving at a definitive diagnosis.

\section{Materials and methods}

This retrospective study was based on 36 iris biopsies from patients who were suspected of having a malignant tumour. Eighteen of these showed the typical features of a malignant melanoma and 10 cases showed unequivocal histological evidence of a leiomyoma. The remaining 8 cases were tentatively considered to be leiomyomas because of the presence of occasional myoglial fibres and the absence of any obvious pigmentation.

The histochemical techniques for the demonstration of oxytalan fibres were controlled by using tissues from the lower jaw of a rat. The incidence and distribution of oxytalan fibres in normal human iris, ciliary body, and choroid were studied by using fresh necropsy material. All material was fixed in $10 \%$ formol-saline, the rat jaw having been demineralised in a formic acid/formaldehyde solution and the processed tissue was embedded in paraffin. Sections were stained by Verhoeff's haematoxylin method, and by orcein and aldehyde fuchsin. In all cases parallel sections were preoxidised with a $10 \%$ solution of peroxymonosulphate for 60 minutes. Additional sections from each specimen were stained with haematoxylin and eosin, Gomori's reticulin stain, the periodic acid Schiff reaction, and by phosphotungstic acid-haematoxylin. Electron microscopy was carried out in selected cases, sections from Araldite-embedded material being stained with uranyl acetate and lead citrate and examined by JEM-100C instrument.

In a pilot study we found that orcein stained oxytalan fibres rather weakly, and, since the fibres were stained a brownish colour, they were not easily identified in pigmented tumours. Moreover, transversely cut oxytalan fibres may be confused with melanin pigment. Orcein staining was thus unsatisfactory for the demonstration of oxytalan in the iris, and only those results obtained by aldehydefuchsin staining will be referred to.

\section{Results}

Oxytalan fibres were not demonstrated in normal iris but were always present in the ciliary body and choroid. A section stained with aldehyde-fuchsin was considered positive for oxytalan fibres only when brilliant purple delicate fibres were demonstrated. Sections which were not previously oxidised showed the presence of aldehyde-fuchsin-positive elaunin fibres in 10 out of 36 iris tumours. These fibres stained a weakly positive colour and were present in the media of large blood vessels and among the tumour cells of leiomyomas. In all cases oxytalan fibres were more abundant in those areas which contained elaunin fibres.

Smooth muscle fibrils were identified by phosphostungstic acid-haematoxylin (PTAH) staining, a known case of a leiomyoma of the uterus acting as a control. In tumours where PTAH staining revealed the presence of large numbers of intracellular myoglial fibrils (Fig. 1), oxytalan fibres were numerous in the stroma (Fig. 2). Furthermore, in some cases the cytoplasm of the dilator muscles appeared to stain with aldehyde fuchsin following oxidation, suggesting that they may contain soluble precursors of oxytalan fibre. It is possible, however, that the actomyosin molecules in myoglial fibres themselves become reseptive to aldehyde fuchsin following oxidation.

In melanocytic tumours of the iris oxytalan fibres were present only in small numbers and were usually confined to the regions of the sphincter and dilator muscles and the media of large blood vessels where smooth muscle is easily demonstrable (Fig. 3). In one tumour which extended into the cornea, however, oxytalan fibres were found in the substantia propria adjacent to the tumour (Fig. 4). This possibly reflects the propensity of the cornea to accumulate these fibres in response to a variety of pathological injuries ${ }^{22}$ rather than a tumourspecific response. One tumour which had been diagnosed as a leiomyosarcoma recurred 5 years 


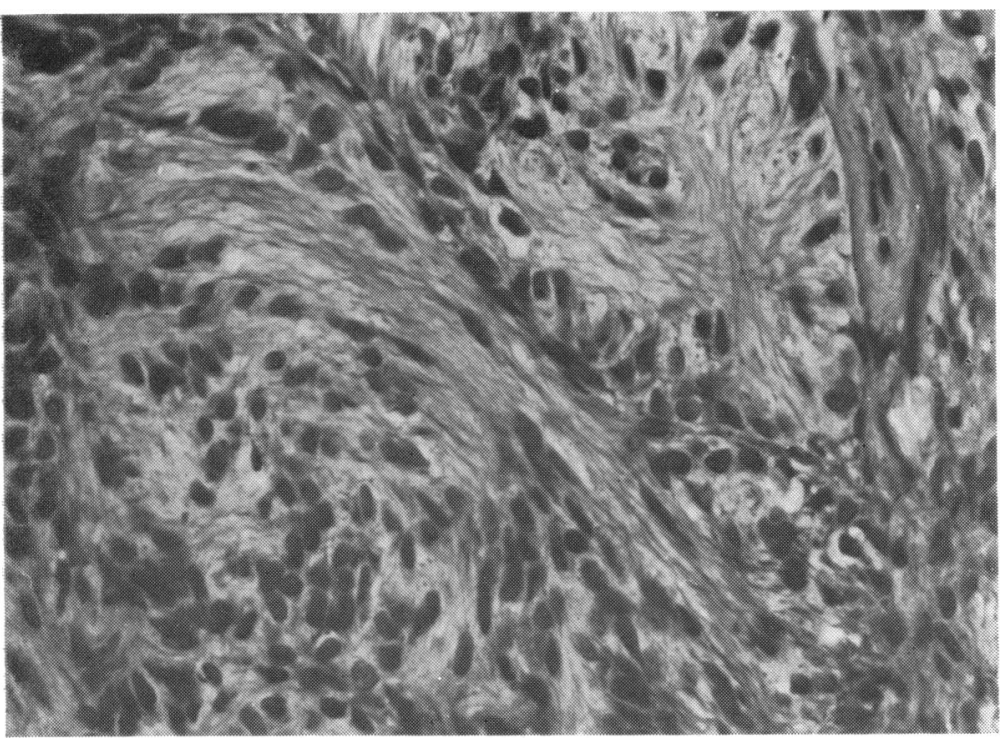

Fig. 1 Section of a leiomyoma of the iris stained with PTAH, demonstrating the intracytoplasmic myoglial filaments. $(\times 660)$.

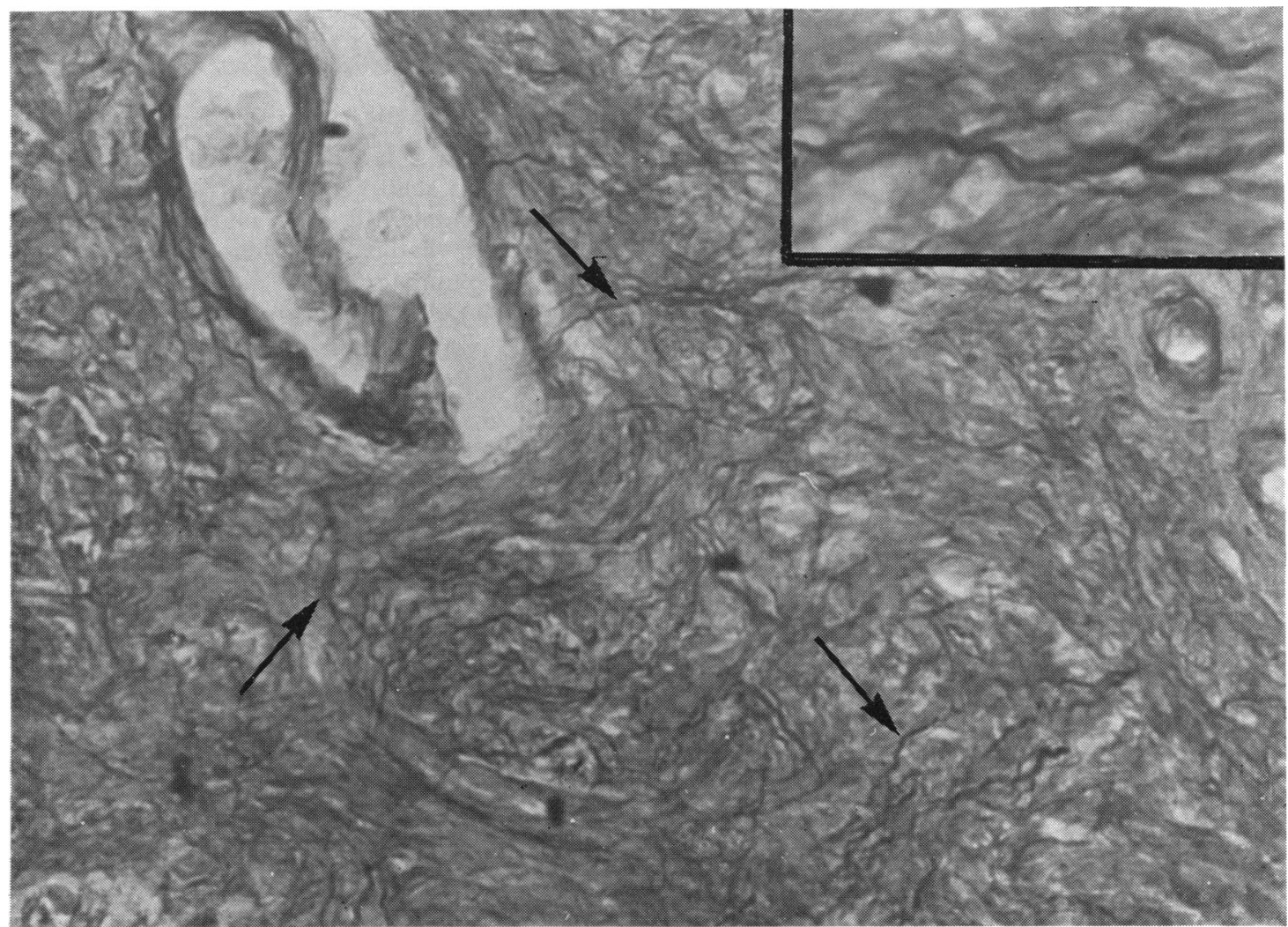

Fig. 2 Section of a leiomyoma of the iris showing darkly stained extracellular oxytalan fibres (arrows). $(\times 960)$. The inset shows the same fibres under higher magnification). 
Fig. 3 Section of a malignant melanoma of the iris. Note that the oxytalan fibres are present only in association with the blood vessels. $(\times 680)$.

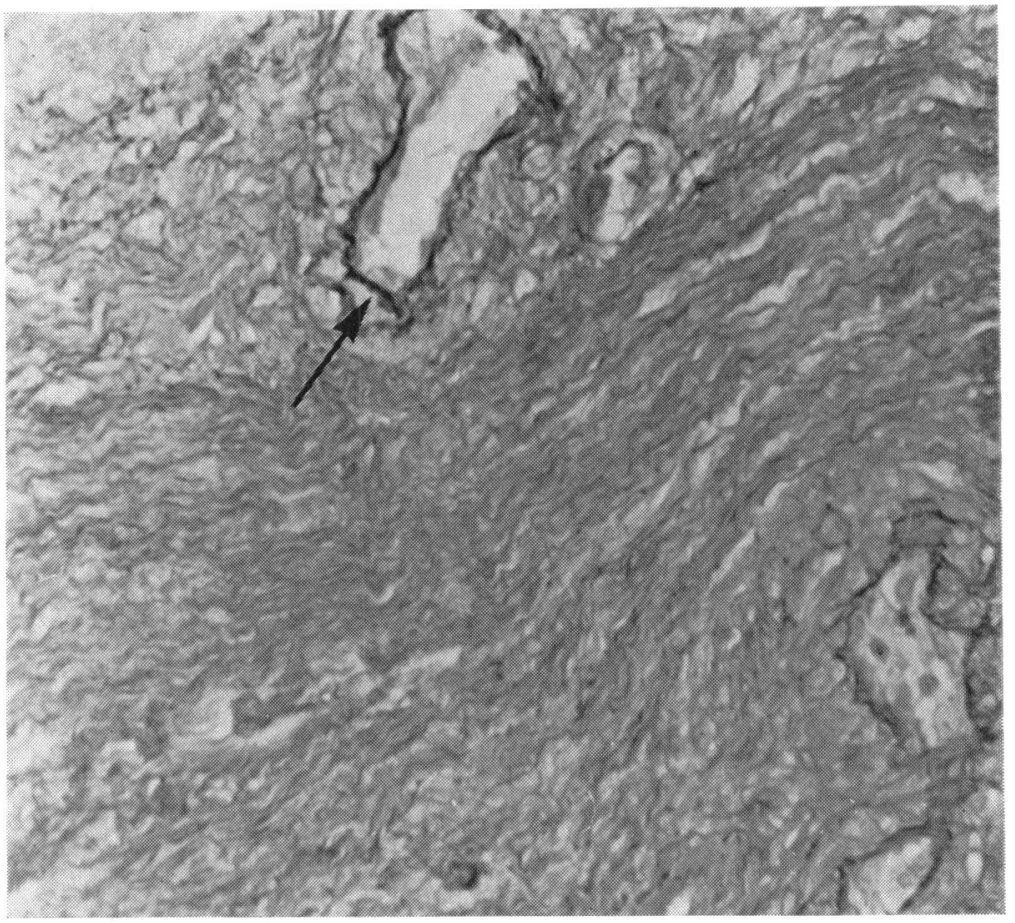

later. The enucleated eye now showed a typical diffuse, infiltrating, pigmented malignant melanoma. The patient died at a later date with liver metastases. Stained sections of the recurrent iris tumour showed occasional oxytalan fibres in the region of the dilator and sphincter muscles, but not in association with the tumour. In cases of melanocytic tumours that arise from the root of iris, there may be an abnormal accumulation of oxytalan fibres which can be traced to the ciliary body, which, unlike the iris, normally has a rich supply of oxytalan and elaunin fibres. Conversely, smooth muscle tumours of the iris were found to be rich in oxytalan fibres usually associated with thick bundles of collagen both between and around the tumour cells. The fibres were arranged either singly or in bundles of varying length. The short fibres were usually thick and curved and sometimes ended in a club-like swelling. The long fibres were usually thin and in many instances coalesced to form bundles. In the region of the dilator muscles they often ran a wavy course parallel to the pigment epithelium of the iris, and similar bundles were also found in the region of the sphincter muscle. The oxytalan fibres not infrequently showed a branching pattern in both the smooth muscle tumours of the iris and the uterus. Although the arrangement of these fibres in the smooth muscle tumours of the iris usually varied, they sometimes showed a honeycomb pattern such as is seen in uterine leiomyomas.

The oxytalan fibres demonstrated in the present study failed to stain with Gomori's reticulin stain, Masson's trichome, PAS, and phosphotungstic acid haematoxylin. Mature elastic tissue was not found in any of the tumours.

The presence of oxytalan fibres within a leiomyoma was confirmed by electron microscopy (Figs. 5 and 6).

\section{Discussion}

A smooth muscle tumour is mesodermal in origin except in the iris, where the lesion arises from the dilator and sphincter muscles, which originate from multipotential neuroectodermal cells of the outer layer of the optic vesicle. This layer also gives rise to the pigment epithelium of the retina and the ciliary body, and in the iris there is a transition to smooth muscle. Since it is well established that melanocytes arise from the neural crest, ${ }^{23}$ it would appear that melanocytic as well as smooth muscle tumours of the iris have a common ancestry in the neuroectoderm (Fig. 7). It is not surprising, therefore, that these tumours share similar potentials for morphological differentiation and dedifferentiation. $^{45}$ As stated previously their histological features may overlap, making their differentiation difficult. This difficulty in differentiation between 


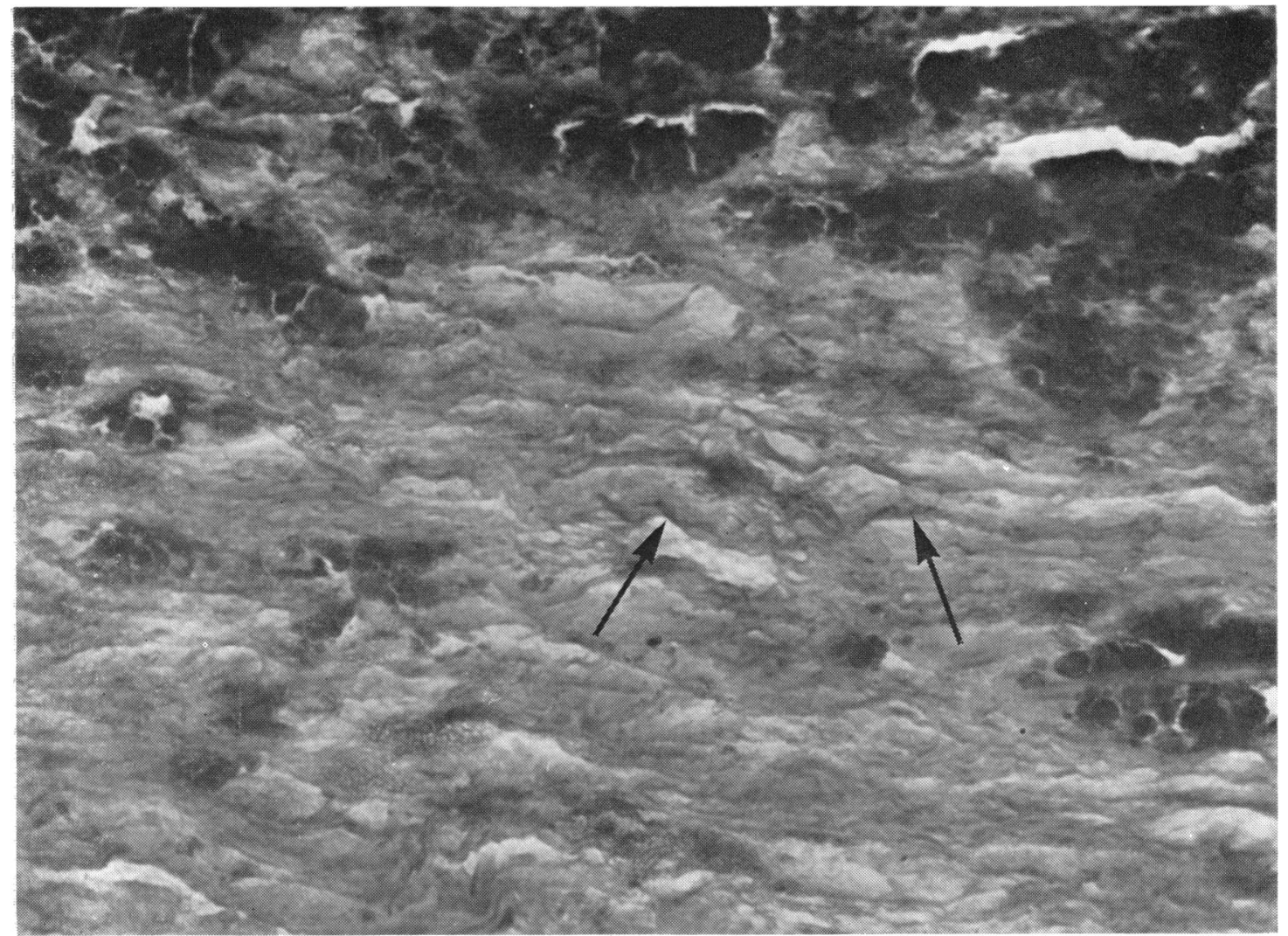

Fig. 4 Section of the cornea infiltrated by malignant melanoma originating within the iris. There are some oxytalan fibres in the corneal stroma which were not seen, however, in the main tumour. $(\times 960)$.

leiomyoma and melanoma of the iris is accentuated by the regular spindle cells devoid of mitotic figures characteristic of the latter tumour. Furthermore, although leiomyomata elsewhere in the body are generally nonpigmented, some smooth muscle tumours of the iris may contain melanin, especially those arising from the dilator muscle, which, in contrast to the sphincter pupillae, shows only partial differentiation. ${ }^{524}$ On the other hand many melanocytic tumours lack pigment or are only lightly pigmented, so that differentiation based on the pigment content alone is impossible. Similarly intranuclear cytoplasmic inclusions, which are a feature of spindle cell melanoma of the uvea, ${ }^{25}$ may also be present in leiomyoma of the iris.

Although in the past the demonstration of myoglial fibrils in spindle cell tumours of the iris has been regarded as the most important criterion in the diagnosis of a leiomyoma, recent immunological and electron microscopical studies have shown that non-muscle tissues of the eye as well as spindle cell melanomata also contain similar fila- ments. ${ }^{11}$ It is clear, therefore, that the presence of myofilaments alone cannot be regarded as a pathognomonic feature of leiomyoma. However, when myoglial fibrils are present together with other histological characteristics of a smooth muscle tumour, i.e., interlacing elongated spindle cells, palisading cigar-shaped nuclei, absent pigmentation, and rich vascularity, there is usually no difficulty in diagnosis. But there are cases in which the histology is in every way typical of a leiomyoma but where myoglial fibrils cannot be demonstrated. ${ }^{4}$ Moreover in some cases of malignant melanoma of the iris there may be secondary hyperplasia and hypertrophy of the sphincter and dilator muscles due to neoplastic infiltration, and it has been suggested that uveal melanomas produce a growth-stimulating substance that can stimulate the growth of normal uveal cells. ${ }^{26}$ These hyperplastic smooth muscle cells usually show myoglial fibrils when stained with PTAH, which may lead to a mistaken diagnosis of leiomyoma.

Although melanoma and leiomyoma share the 


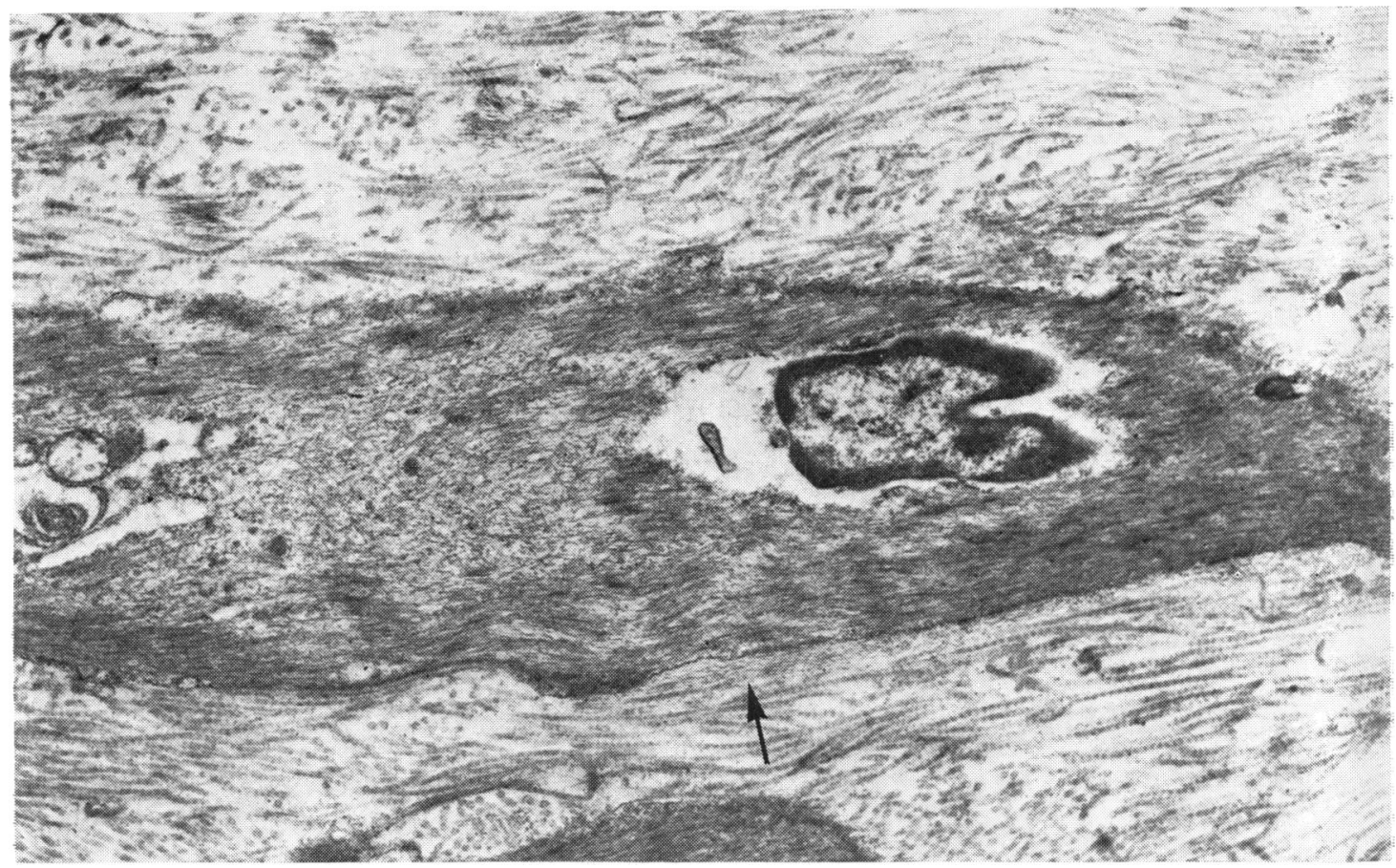

Fig. 5 Electron micrograph of a leiomyoma showing intracellular actomyosin filaments. Immediately outside the muscle cell there is a collection of oxytalan microfibrils (arrow) which appear very much smaller than the prominent collagen fibres. $(\times 14500)$.

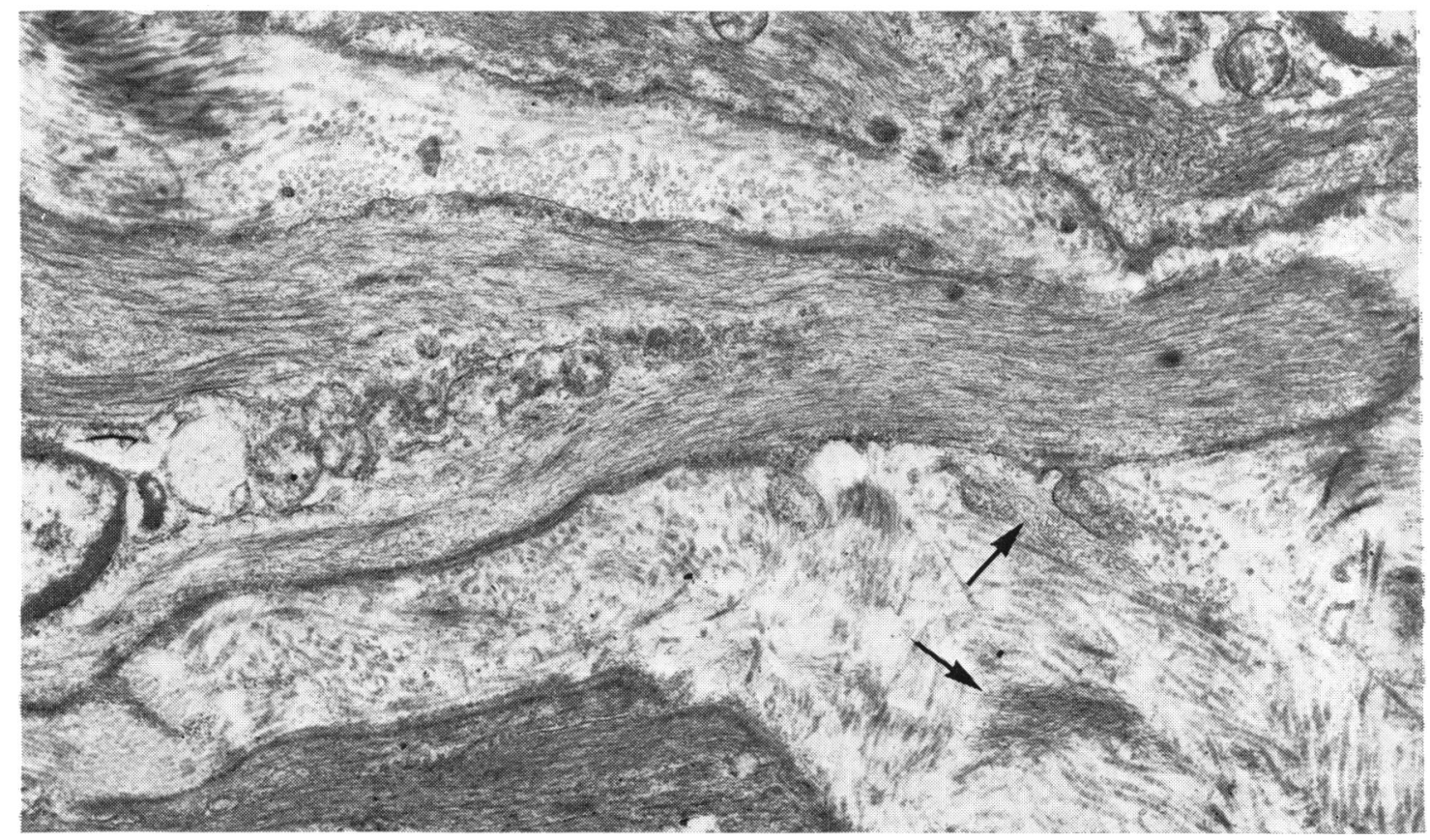

Fig. 6 Oxytalan microfibrils in another leiomyoma. The electron micrograph shows very clearly the localised collections of these fibrils (arrows). $(\times 14500)$. 


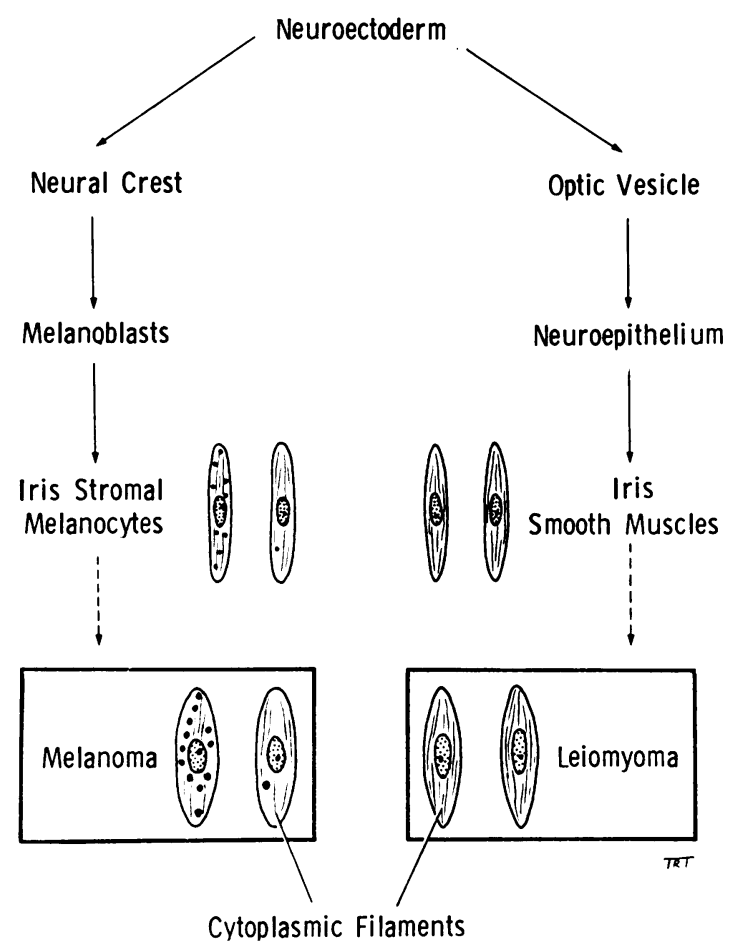

Fig. 7 To show the common ancestry and the morphological relationship between melanoma and leiomyoma of the iris. same histogenesis because of their embryological origin, there are differences in their clinical behaviour. While leiomyomatous tumours may be locally invasive, they do not metastasise. ${ }^{4517}$ In addition, we have not recorded any instance of metastasis in a study of over 200 primary tumours of the iris in which the patients were followed up for periods between 7 and 30 years. Since malignant melanomas of the iris do metastasise occasionally $12-16$ it is important to differentiate these 2 tumours for prognostic reasons. In the present study we have included only those leiomyomas which satisfied all the criteria of smooth muscle tumours.

Leiomyomatous tumours were rich in oxytalan fibres, while melanocytic tumours were usually devoid of such fibres except in the walls of large blood vessels which normally contain smooth muscle cells. Some melanocytic tumours appeared to contain a few oxytalan fibres, which on close examination were found to be associated with the sphincter and dilator muscles. In no instance, however, did any of the melanocytic tumours contain histochemically recognisable oxytalan fibres between the tumour cells. Ultrastructural examination of tissue from 3 such cases failed to demonstrate the characteristic $12 \mathrm{~nm}$ diameter oxytalan fibrils.

A feature of great interest is the intimate relationship between oxytalan fibres and smooth muscle cells. We found that this close proximity was a constant feature, not only in the leiomyomas of

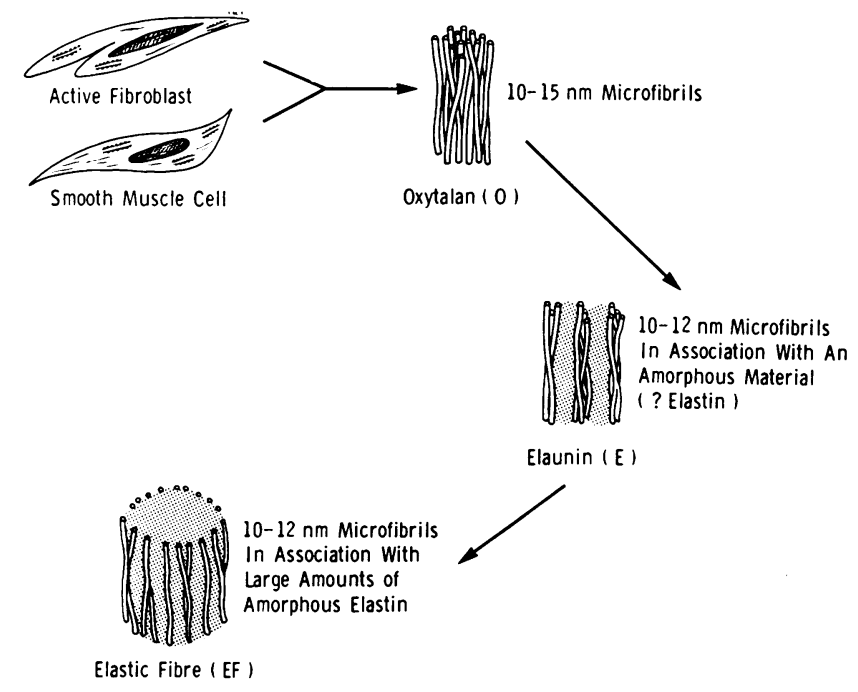

Fig. 8 Diagram speculating on the origin and maturation of elastic fibres (i.e., $O \rightarrow E \rightarrow E F$ ). The maturation process may be arrested at $O$ or $E$ in both normal and abnormal tissues.

SPECULATIVE DIAGRAM TO SHOW THE ORIGIN AND MATURATION OF ELASTIC FIBRE (i. e. O-E-EF ). THE MATURATION PROCESS MAY BE ARRESTED AT'O'OR'E' IN NORMAL AS WELL AS PATHOLOGICAL TISSUES 
the iris but also in leiomyomas of the uterus and in the hypertrophic blood vessels of the tumours. It is relevant in this context that in an experimental study performed on growing rats ${ }^{27}$ the authors reported autoradiographical evidence of the incorporation of labelled proline in proteins synthesised by smooth muscle cells. They also demonstrated that these cells were responsible for the elaboration of the three major constituents of connective tissue, i.e., collagen and the 2 components of elastic fibre, the microfibrils and elastin. The role of smooth muscle in the production of connective tissue in man has also now been confirmed. ${ }^{29}$ Since oxytalan fibres are currently considered to be a member of the normal elastic fibre system, ${ }^{20}{ }^{21}$ it is conceivable that these fibres are also produced by smooth muscle cells. Furthermore, the intimate relation of these fibres with smooth muscle, the presence of elaunin, and the occasional staining of smooth muscle cells by aldehyde fuchsin following oxidation are points in favour of oxytalan fibres being the product of smooth muscle cells (Fig. 8).

Since mature elastic fibres were not present in any of our cases, it is possible that oxytalan fibres are either a separate class of elastic tissue or simply represent an arrested maturation. The appearance of oxytalan fibres was not related to time because we observed them in tumours as early as 3 weeks and as late as 14 years.

In the case of malignant melanoma of the iris which infiltrated the cornea, the origin of oxytalan fibres in the corneal lamellae is obscure, but it is possible that there are cells other than fibroblast and smooth muscle (e.g., keratocytes) that can synthesise these fibres (Fig. 8).

Experience gained from the malignant melanoma which was originally diagnosed as a leiomyosarcoma illustrates that the incidence and distribution of oxytalan fibres are reliable diagnostic criteria. The present study also suggests that oxytalan fibres in the tumours of the iris are the product of smooth muscle cells.

\section{References}

1 Verhoeff FH. A case of mesoblastic leiomyoma of the iris. Arch Ophthalmol 1923; 52: 132-9.

2 Li TM. Primary ring sarcoma of the iris. Am J Ophthalmol 1923; 6: 545-56.

3 Heath P. Tumors of the iris muscle. Trans Am Ophthalmol Soc 1951; 49: 147-64.

4 Ashton N. Primary tumours of the iris. Br J Ophthalmol $1964 ; 48$ : 650-68.

5 Reese AB. Tumors of the Eye, 3rd ed. New York: Harper and Row, 1976: 298-301.
6 Erdbrink WL, Harbert F. Leiomyoma of the iris. Arch Ophthalmol 1955; 53: 643-8.

7 Hogan MJ, Alvarado JA, Weddell JE. Histology of the Human Eye. An Atlas and Text Book. Philadelphia: Saunders, $1971: 33-5$.

8 Trenchev $\mathrm{P}$, Sneyd P, Holborow EJ. Immunofluorescent tracing of smooth muscle contractile protein antigens in tissues other than smooth muscle. Clin Exp Immunol 1974; 16: 125-36.

9 Rahi AHS, Ashton N. Contractile proteins in retinal endothelium and other non-muscle tissues of the eye. Br J Ophthalmol 1978; 62: 627-43.

10 Lazarides E. Intermediate filaments as mechanical integrators of cellular space. Nature 1980; 283: 249-56.

11 Rahi AHS, Garner A, Malaty AHA. Contractile protein antigens in the cells of malignant melanoma of the choroid and their diagnostic significance. Br J Ophthalmol 1978; 62: 394-401.

12 Duke JR, Dunn SN. Primary tumors of the iris. Arch Ophthalmol 1958; 59: 204-14.

13 Reese AB, Cleasby GW. The treatment of iris melanoma. Am J Ophthalmol 1959; 47: 118-25.

14 Apt L. Uveal melanomas in children and adolescents. Int Ophthalmol Clin 1962; 2: 403-10.

15 Zimmerman LE. Histopathological considerations in management of tumours of the iris and the ciliary body. Ann Inst Barraquer 1971-2; 10: 27-57.

16 Sunba MSN, Rahi AHS, Morgan G. Tumours of the anterior uvea: I. Metastasizing malignant melanoma of the iris. Arch Ophthalmol 1980; 98: 82-5.

17 Dugmore WN. 11-year follow-up of a case of iris leiomyosarcoma. Br J Ophthalmol 1972; 56: 366-7.

18 Fullmer HM, Lillie RD. The oxytalan fiber: A previously undescribed connective tissue fiber. J Histochem Cytochem 1958; 6: 425-30.

19 Fullmer HM. Differential staining of connective tissue fibers in areas of stress. Science 1958; 127: 1240.

20 Fullmer HM, Sheetz JH, Narkates AJ. Oxytalan connective fibers: a review. J Oral Pathol 1974; 3: 291-316.

21 Cotta-Pereira G, Fuerra Rodrigo F, Bittencourt-Sampaio S. Oxytalan, elaunin and elastic fibers in the human skin. J Invest Dermatol 1976; 66: 143-8.

22 Alexander RA, Garner A. Oxytalan fibre formation in the cornea: a light and electron microscopical study. Histopathology 1977; 1: 189-99.

23 Weston JA. The migration and differentiation of neural crest cells. Adv Morphogen 1970; 8: 41-124.

24 Fleming N. A case of pigmented leiomyoma of the iris. Br J Ophthalmol 1948; 32: 885-92.

25 Sunba MSN, Rahi AHS, Morgan G. Tumours of the anterior uvea. II. Intranuclear cytoplasmic inclusions in malignant melanoma of the iris. Br J Ophthalmol 1980: 64: 453-6.

26 Colenbrander MC. Mathematical diffusion of choroidal sarcoma infiltration. Ned Tijdschr Geneesk 1952; 96: 1235-7.

27 Ross R, Klebanoff SJ. The smooth muscle cell. I. In vivo synthesis of connective tissue proteins. J Cell Biol 1971: 50: $159-97$.

28 Ross R. The smooth muscle. II. Growth of smooth muscle in culture and its formation of elastic fiber. $J$ Cell Biol 1971; 50: 172-86.

29 McCullagh KG, Duance VC, Bishop KA. The distribution of collagen types I, III and V in normal and atherosclerotic human aorta. $J$ Pathol 1980; 130: 45-55. 